\title{
El sistema de canales y camellones prehispánico del golfo de Urabá, noroccidente de Colombia. Un reporte arqueológico y geográfico preliminar
}

\section{The prehispanic ridged field system in the Gulf of Urabá, northwestern Colombia. An archaeological and geographical preliminary report}

\author{
(1) William A. Posada-Restrepo*, (1) Bibiana Cadena-Duarte,

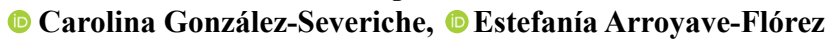 \\ Departamento de antropología, Universidad de Antioquia, Medellín, Colombia
}

\begin{abstract}
Resumen
Los sistemas de canales y camellones construidos en tierra durante la época prehispánica fueron una de las alteraciones geomorfológicas más comunes para el control de las inundaciones y la producción agrícola en distintas regiones de América. En Colombia, si bien se han estudiado desde hace varias décadas los hallazgos asociados a los ríos Sinú y San Jorge, la presencia de nuevas estructuras en el golfo de Urabá había permanecido ignorada por la comunidad científica. En este artículo se describen de forma preliminar estos hallazgos en términos de su morfometría y patrones espaciales, se hace una contextualización inicial en el ámbito de la arqueología del golfo de Urabá y de la geografía particular de la cuenca del río León y se plantean algunas hipótesis preliminares considerando las posibilidades de articulación de dichos estudios con las dinámicas territoriales actuales de la región de Urabá.

Palabras clave: Golfo de Urabá; arqueología; camellones prehispánicos.
\end{abstract}

\begin{abstract}
The ridged field systems built on land during the prehispanic periods were some of the most common geomorphic alterations for floods control and agricultural production in different regions of the Americas. In Colombia, although the findings associated with the Sinú and San Jorge Rivers have been studied for several decades, new structures located in the Gulf of Urabá had remained ignored by the scientific community. This paper makes a preliminary description of these findings focusing on their morphometry and spatial patterns, as well as their contextualization in the Urabá archaeology and the geography near to the León River basin. Based on descriptions and previous research, some preliminary hypotheses are proposed, which highlight the potential linkage between these studies and the current dynamics of the Urabá region.
\end{abstract}

Keywords: Urabá Gulf; archaeology; prehispanic ridges.

\section{Introducción}

A mediados de la década del sesenta, Parsons \& Bowen (1966) reportaron en la costa norte de Colombia una serie de plataformas alargadas en la cuenca media del río San Jorge, las cuales estaban separadas por zanjas o canales paralelos que formaban un sistema de estructuras en tierra que se extendían a lo largo de miles de hectáreas en las regiones de Córdoba, Sucre y Bolívar. A estas estructuras les atribuyeron un origen prehispánico, lo que llamó la atención de varios arqueólogos que reconocieron en ellas una importante obra de ingeniería hidráulica con un período de uso de aproximadamente dos mil años (Plazas \& Falchetti,
1981; Plazas, et al., 1993, 1988; Reichel - Dolmatoff, 1997). A partir del hallazgo se plantearon varias hipótesis sobre el contexto social, político, económico y ambiental que favoreció su desarrollo y que todavía hoy son motivo de estudio y profundas discusiones (Rojas, 2010; Rojas \& Montejo, 2006).

*Correspondencia:

William A. Posada-Restrepo; williama.posada@udea.edu.co

Recibido: 13 de marzo de 2019

Aceptado: 5 de agosto de 2019

Editor: Elizabeth Castañeda 
A pesar de su visibilidad y de los muchos estudios que se han hecho sobre estas estructuras arqueológicas en Colombia, llama la atención la inmensa zona de estructuras similares que también existe en el golfo de Urabá, distante unos $200 \mathrm{~km}$ al suroeste de la hoya del río San Jorge, y que pasó inadvertida durante años entre las extensas praderas y humedales de la región. Aunque ya se habían realizado exploraciones arqueológicas en las cuencas bajas de los ríos León y Mulatos (Román, 1985; Poveda, 2001), donde actualmente se encuentran las estructuras mejor conservadas de todo el golfo, tan solo en un breve reporte del coleccionista antioqueño Luis Vélez (2011), se describe la presencia de una amplia red de canales y camellones en la región de Urabá, entre los municipios de Turbo y Chigorodó en Antioquia y de Riosucio en Chocó, muy cerca a la vía panamericana que está prevista para conectar con Panamá.

Aunque dicho reporte parece no haber tenido un impacto significativo entre científicos o aficionados, lo cierto es que reviste una importancia mayor debido a que conecta los hallazgos de tecnologías similares en las regiones del río San Jorge en Colombia y de Gran Coclé en Panamá, además de aportar nuevos datos sobre la economía, la ecología y la organización sociopolítica de las poblaciones responsables de su construcción y aprovechamiento. Toda esta información, vista en perspectiva, representa un aporte invaluable para el desarrollo cultural y ambiental de la región de Urabá, históricamente azotada por el conflicto interno y el abandono estatal, y plantea nuevas formas de gestión y aprovechamiento de los recursos culturales en su jurisdicción.

Si bien este tipo de estructuras no es exclusivo de la costa norte de Colombia, ya que formas similares se han registrado también en el interior del país y en la costa Pacífica (Broadbent, 1968; Bruhns, 1981; Salgado, 1986; Boada,
2006; Patiño, 2006; Sánchez, 2007), sí representan una adaptación particular dadas las características geográficas del golfo de Urabá, cuya localización estratégica, hidrodinámica y biodiversidad habrían incidido en el desarrollo de una tecnología monumental, ampliamente difundida durante la época prehispánica en gran parte del trópico americano.

La macrorregión de Urabá-Darién ha sido señalada en repetidas ocasiones como un territorio culturalmente diverso y geopolíticamente estratégico, tanto por su situación geográfica como por sus recursos naturales (Bray, 1990; Linne, 1929; Parsons \& Bowen, 1966; ReichelDolmatoff, 1997; González, 2011). Desde el punto de vista arqueológico, la extensión de esta área desde el istmo de Panamá hasta las planicies costeras del Caribe colombiano, se considera un gran foco cultural en el que acontecieron constantes eventos de interacción social, control territorial y adaptación a los ecosistemas de tierras bajas, los cuales sentaron las bases para la colonización de las regiones en el interior de Centroamérica y Suramérica (Bray, 1990; Helms, 1979; Plazas, et al., 1988; Reichel-Dolmatoff, 1997).

\section{Área de estudio}

Si bien durante el ejercicio de interpretación de las fotografías de este hallazgo se localizaron estructuras de tierra en varios sectores del golfo de Urabá, desde el municipio de Necoclí, en el noreste, hasta el municipio de Ríosucio, en el suroeste, este artículo se limitará a describir la zona de mayor concentración de estructuras, localizada al sur del golfo, sobre la llanura de inundación del río León, en la parte mediabaja de la cuenca. Este sector constituye un paisaje plano, confinado por la serranía del Darién al oeste y la serranía de Abibe al este, topográficamente interrumpido por los cerros El Cuchillo y Lomas Aisladas, los cuales constituyen las únicas elevaciones en el interior de la llanura (Figura 1).

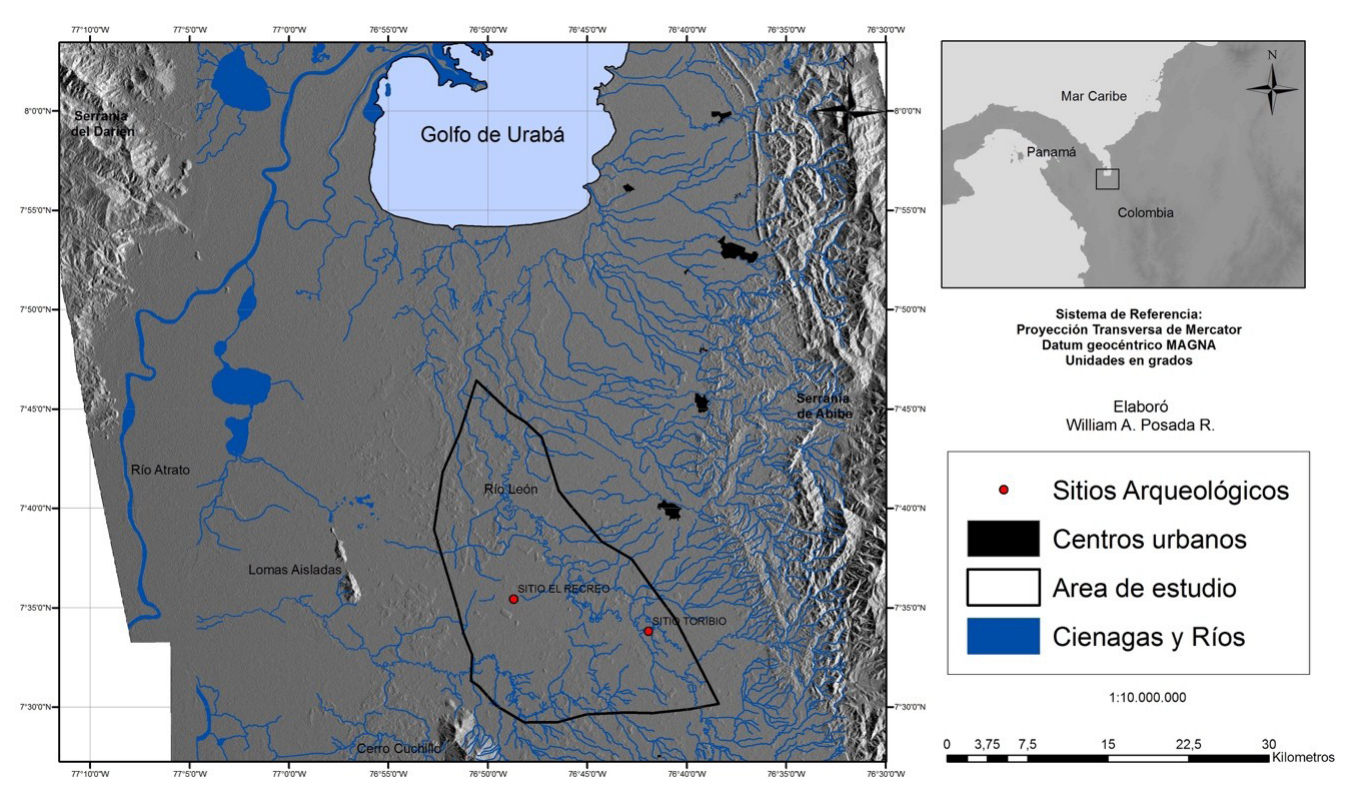

Figura 1. Localización del área de estudio 
La mayoría de las estructuras arqueológicas están asociadas directamente con el río León, entre las poblaciones de Nueva Colonia, Lomas Aisladas y Barranquillita, en el departamento de Antioquia. Sin embargo, se observan otros patrones en cercanías del río Tumaradocito, junto a las poblaciones de Macondo y Blanquiset, actualmente adscritas al departamento del Chocó.

Esta zona se encuentra en la cota de $8 \mathrm{~m}$ s.n.m. y se caracteriza por unas condiciones sumamente húmedas, con un régimen de precipitación unimodal de aproximadamente $2.400 \mathrm{~mm}$ anuales, y un único período seco entre los meses de enero y abril. Dicha condición, aunada a una topografía plana o casi plana (0-5\% de pendiente), hace que los suelos se mantengan saturados durante la mayor parte del año, favoreciendo los procesos de escorrentía y el flujo de sedimentos en la cuenca (Guzmán \& Ceballos, 2001). Según el Instituto Geográfico Agustín Codazzi (2007), tales procesos aportan muchos nutrientes orgánicos al suelo, pero el flujo de agua conduce a procesos de hidromorfismo y gleyzación, lo que da lugar a la formación de Inceptisoles fluviales eutróficos que, pese a su bajo nivel de desarrollo, posee propiedades químicas con óptimos valores para la actividad agrícola y pecuaria.

La productividad del suelo y las características hidroclimáticas de la región han motivado a algunos habitantes actuales a construir permanentemente zanjas y jarillones para drenar el terreno en aras del desarrollo de proyectos agropecuarios. Esto no solo ha alterado la dinámica general de la cuenca, sino también los contextos arqueológicos y los asentamientos modernos que se ven enfrentados a competir por el desarrollo de estrategias de drenaje cada vez más eficientes.

Hoy habitan el área de estudio dos comunidades afrodescendientes, una comunidad indígena de la etnia Embera Katío, aún sin título de resguardo, y algunos campesinos cordobeses, chocoanos y antioqueños del interior que concentran gran parte de las tierras productivas de la región. El uso actual del suelo se centra en la ganadería extensiva, a menudo de hatos bufalinos, con algunas pocas hectáreas dedicadas a la agricultura de pancoger, el cultivo de arroz y la conservación de algunos bosques maderables.

Pese a los hechos de violencia y desplazamiento forzado ocurridos en las últimas décadas, hoy en día los actores armados enfrentan la organización de las comunidades y la apertura de nuevos espacios de participación con el apoyo de organizaciones no gubernamentales y corporaciones estatales.

\section{Metodología}

Las estructuras se detectaron mediante la revisión de imágenes de satélite disponibles de forma gratuita en Google Earth y Apple Maps, así como imágenes DEM Alos Palsar, con una resolución de 12,5 metros por píxel. Con ellas se hizo una caracterización preliminar de los camellones en cuatro sectores con estructuras bien conservadas y de distinto patrón, teniendo en cuenta sus dimensiones y características como la orientación y la forma. Además, se realizaron tres visitas de campo, con el fin de entrevistar a los habitantes de la región, reconocer bien las estructuras prehispánicas y recolectar en superficie artefactos y otras evidencias. Una vez localizadas las estructuras, se hicieron recorridos a pie por sectores donde los habitantes habían reportado artefactos cerámicos y líticos para recoger en la superficie fragmentos cerámicos y carbón en suelos y perfiles expuestos. Los materiales arqueológicos se sometieron a la respectiva curaduría y clasificación en el laboratorio. Por último, las fechas establecidas mediante carbono 14 (C14) en otros estudios se calibraron con el programa Calib 7 (Stuiver \& Reimer, 1993.) empleando la curva de calibración IntCal13 y un intervalo de probabilidad de $2 \sigma$.

\section{Resultados preliminares}

Mediante la interpretación de las fotografías se determinó un área de aproximadamente $44.000 \mathrm{Ha}$ de canales y camellones en la cuenca del río León, probablemente de mayor extensión hacia el río Atrato, donde las imágenes satelitales carecen de resolución suficiente, pero distribuidas más claramente en un polígono de morfología triangular con las siguientes coordenadas en cada uno de sus vértices: vértice occidental: $7^{\circ} 31^{\prime} 19,60^{\prime \prime}$ norte y $76^{\circ} 50^{\prime} 51,06^{\prime \prime}$ oeste; vértice oriental: $7^{\circ} 30^{\prime} 09,77^{\prime \prime}$ norte y $76^{\circ} 38^{\prime} 24,12^{\prime \prime}$ oeste, y vértice norte: $7^{\circ} 46^{\prime} 26,63^{\prime \prime}$ norte y $76^{\circ} 50^{\prime} 35,37^{\prime \prime}$ oeste.

Según las descripciones hechas por Denevan (1970), se reconocieron en el área de estudio sistemas de tipo "caño", "escalera" y "ajedrezado" (Figuras 2a,b,c,d, respectivamente), siendo este último el más común. Así mismo, se encontraron cuatro tipos de camellones según su morfometría: lineales, variados (en forma de L, U y de tridente) (Figura 3), poligonales y curvos. Los camellones lineales fueron los más frecuentes y sus dimensiones tuvieron un amplio rango, como se puede observar en la Tabla 1. Las estructuras lineales más recurrentes fueron de tamaño mediano, y su presencia se registró a lo largo y ancho del área de estudio. En cuanto a su morfometría transversal, solo se pudo observar que los camellones prehispánicos son de cima relativamente plana, con alturas que oscilan entre los 5 y $40 \mathrm{~cm}$ de alto. Esos atributos los distinguen de los jarillones modernos, cuya altura suele ser mayor a 1,5 metros, presentan cimas redondeadas o ligeramente angulares y no poseen otras estructuras asociadas en un patrón contiguo o paralelo.

Gran parte de las estructuras prehispánicas registradas carece de topografía discernible debido a procesos de alteración que las han afectado a lo largo del tiempo, como la erosión, el arado mecanizado o la colmatación de sedimentos. Esta peculiaridad, señalada también por Denevan (1970), y descrita como estructura de perfil plano, solo es posible verla a gran altura, debido a los cambios de color que presenta la vegetación en función de las diferencias edáficas en los canales y camellones. 
Tras un par de visitas de reconocimiento a la zona, se identificaron dos sitios arqueológicos con material cerámico expuesto, ambos localizados en el área de las estructuras, aunque no directamente sobre ellas. El primer sitio se identificó como El Recreo, situado en la finca del mismo nombre, corregimiento de Lomas Aisladas, municipio de Turbo. La cerámica se encontraba dispuesta superficialmente en los alrededores de la casa principal de la finca. Un breve ejercicio de recolección superficial arrojó un total de 138 fragmentos cerámicos, 16 de ellos correspondientes a bordes y tres,

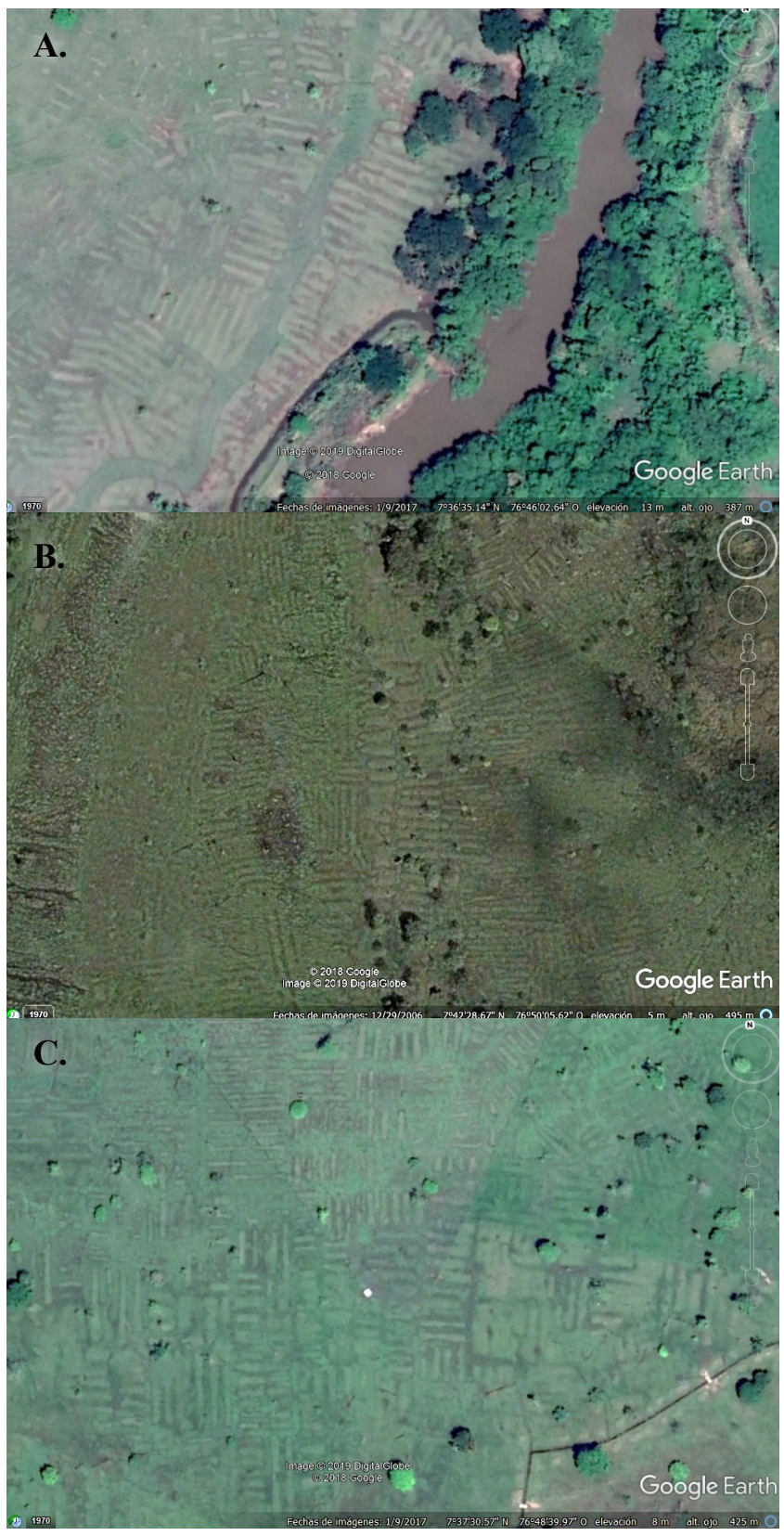

Figura 2A. Patrón de camellones en caño. Imagen tomada el 2 de abril de 2018. B. Patrón escalonado. Imagen tomada el 04 de febrero de 2019. C. Patrón ajedrezado. Imagen tomada el 20 de septiembre de 2018 a fragmentos decorados. Los restos cerámicos describen ollas de borde evertido o directo, labio redondeado, biselado y reforzado. Solo en un caso se registró un borde decorado con dos acanaladuras horizontales a lo largo de la superficie interna (Figuras 4 y 5 ).

Los colores de la pasta son predominantemente naranja con núcleos de cocción internos grises o habanos. La pasta es de estructura porosa, a veces laminar, con desgrasante fino de roca triturada y algunas inclusiones de cuarzo y óxidos de hierro que ocupan un $5 \%$ de la pasta. Si bien las superficies están muy erosionadas, la presencia de restos de engobe y decoración en algunos fragmentos sugiere que las vasijas tenían acabados más elaborados que no resistieron los procesos posteriores a su deposición. Las pocas decoraciones registradas, aparte de las ya mencionadas en el borde, constan de líneas incisas poco profundas y acanaladuras impresas paralelamente sobre segmentos del cuello. Sobresalen en el conjunto cerámico algunos fragmentos con pasta y desgrasante más finos, con espesores de $5 \mathrm{~mm}$ en promedio y color de pasta y engobe marrón (Figura 4, conjunto c).

Contiguo al lugar del hallazgo de los artefactos, están las estructuras más atípicas encontradas en la zona, correspondientes a sistemas reticulados de micro-camellones de 2 x $5 \mathrm{~m}$ aproximadamente (Figura 6). Muchas de estas estructuras son imperceptibles en campo, ya que la mayoría carece de variaciones significativas de altura.

El segundo sitio se denominó Toribio, por su localización cercana al caño que lleva este nombre, muy próxima a la población de Barranquillita, en el municipio de Chigorodó. El sitio fue detectado tras la intervención que varios meses atrás realizó una retroexcavadora para la construcción de un jarillón. Allí se recuperaron más de quinientos fragmentos cerámicos, entre ellos, 15 bordes y un decorado. Según nuestras observaciones, el material cerámico se encontraba sepultado a una profundidad de un metro, aproximadamente; allí, además, se pudo apreciar abundante carbón vegetal estratificado sobre el barranco expuesto del caño.

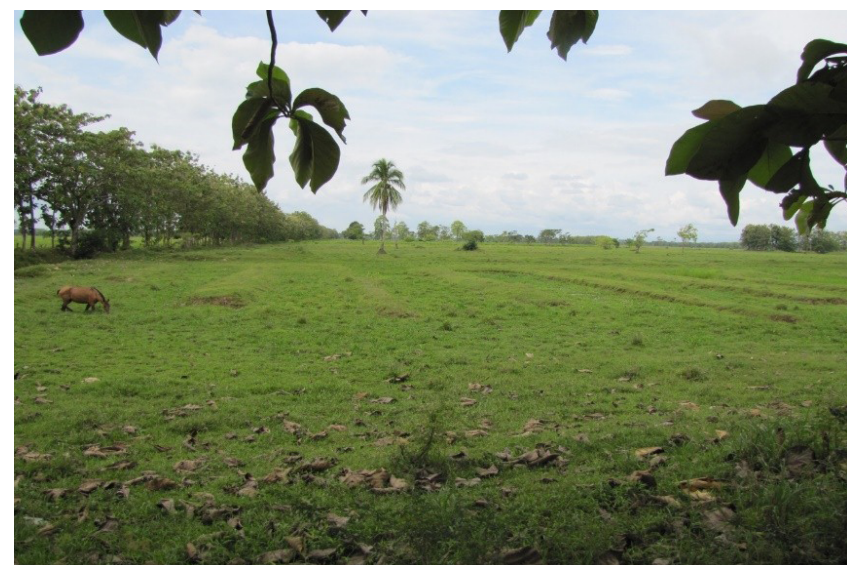

Figura 3. Camellones en forma de U y de tridente (obsérvese el caballo para dar idea de la escala) 
Tabla 1. Dimensiones estimadas en los distintos tipos de camellones

\begin{tabular}{|c|c|c|c|c|c|c|c|c|c|}
\hline \multirow[t]{3}{*}{ Forma } & & \multicolumn{8}{|c|}{ Dimensiones (metros) } \\
\hline & & \multicolumn{4}{|c|}{ Largo } & \multicolumn{4}{|c|}{ Ancho } \\
\hline & & Media & D.E ${ }^{v}$ & Mínimo & Máximo & Media & $\mathbf{D E}^{\mathrm{v}}$ & Mínimo & Máximo \\
\hline \multirow[t]{3}{*}{ Lineal } & Grande & 33,85 & 8,26 & 27,10 & 60,40 & 3,13 & 0,60 & 2,00 & 4,90 \\
\hline & Mediano & 15,86 & 6,54 & 7,50 & 26,90 & 3,07 & 0,70 & 1,70 & 5,90 \\
\hline & Pequeño & 5,62 & 1,30 & 2,50 & 7,45 & 3,13 & 0,90 & 2,60 & 7,50 \\
\hline Variada & & $38,90^{*}$ & 28,3 & 15,00 & 135,00 & 3,46 & 1,40 & 2,20 & 8,90 \\
\hline Poligonales & & $73,10^{* *}$ & 0,70 & 72,50 & 73,60 & 2,90 & 0,40 & 2,60 & 3,10 \\
\hline Curva & & $9,06 * * *$ & 6,21 & 4,60 & 13,46 & - & - & - & - \\
\hline
\end{tabular}

'Desviación estándar, *Longitud; **Perímetro; ***Radio

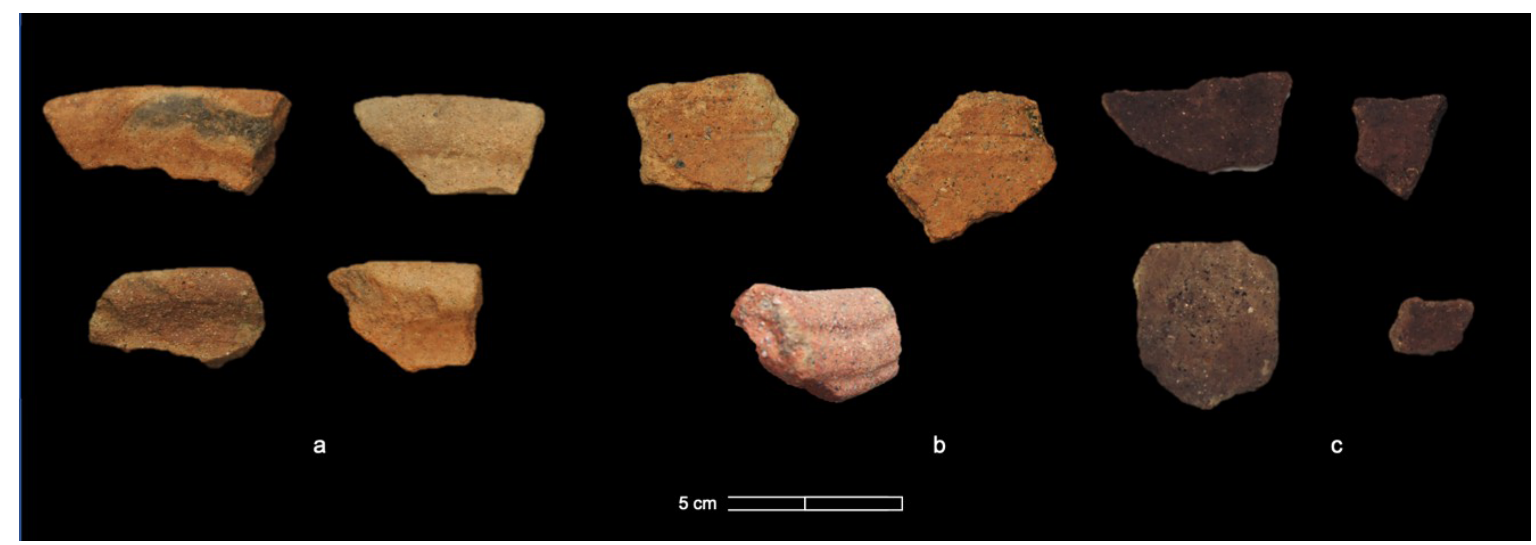

Figura 4. Fragmentos cerámicos del sitio El Recreo. Nótese en el centro de la foto la decoración interna del borde

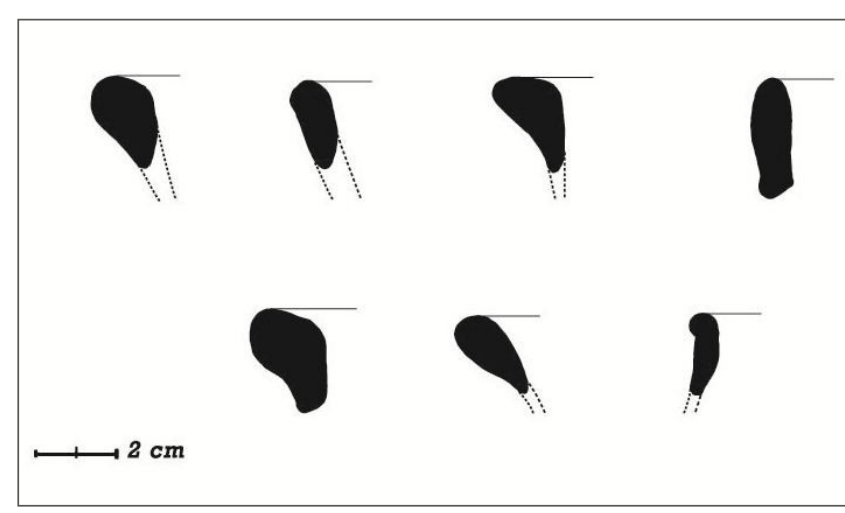

Figura 5. Morfología transversal de bordes en el sitio El Recreo

La cerámica de este sitio guarda estrechas similitudes con la del sitio El Recreo ya mencionado, aunque claramente exhibe una mayor diversidad de formas y tamaños. La presencia de grandes fragmentos cerámicos correspondientes a segmentos de cuerpo, con espesores mayores a un centímetro y con bordes de diámetro aproximado de $20 \mathrm{~cm}$, plantean la existencia de ollas globulares o subglobulares de

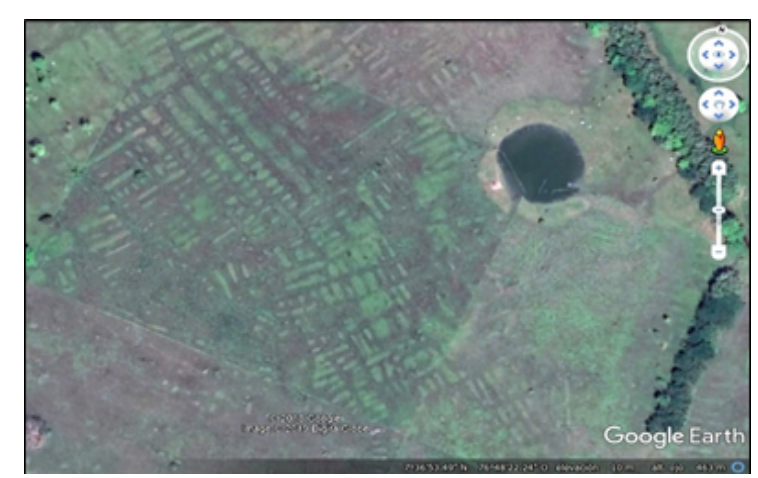

Figura 6 Patrón microrreticulado atípico. Imagen tomada el 4 de marzo de 2019

considerables dimensiones. Algunos bordes son evertidos, y de labio redondeado o biselado como los de El Recreo. Los de labio biselado en Toribio, a diferencia de aquel otro sitio, no son reforzados sino adelgazados y pueden prolongarse horizontalmente hasta $1,5 \mathrm{~cm}$ (Figura 7). Algunos bordes exhiben decoración acanalada en líneas paralelas horizontales, ya sea en la superficie interna o 
externa. Otro artefacto de diagnóstico registrado en este sitio fue un posible fragmento de asa de sección cuadrada y con curvatura abierta, muy distinto a las asas típicas de la alfarería prehispánica de Urabá.

En la pasta dominan los colores naranja y habano, con núcleos de cocción internos de tonos grises a negros. La pasta es igualmente porosa, con desgrasante predominantemente fino, de roca triturada e inclusiones de óxidos de hierro y cuarzo, moderadamente seleccionadas, que ocupan entre un 5 y un $10 \%$ de la pasta. También se conservan algunos restos de engobe en las superficies, pese al alto grado de erosión que presentan. Al igual que en El Recreo, aquí se registraron algunos fragmentos tipológicamente distintos, con pasta y desgrasante más finos, acabados de color marrón y espesores de 5 a $9 \mathrm{~mm}$ (Figura 8 conjunto $\mathrm{c}$ ).

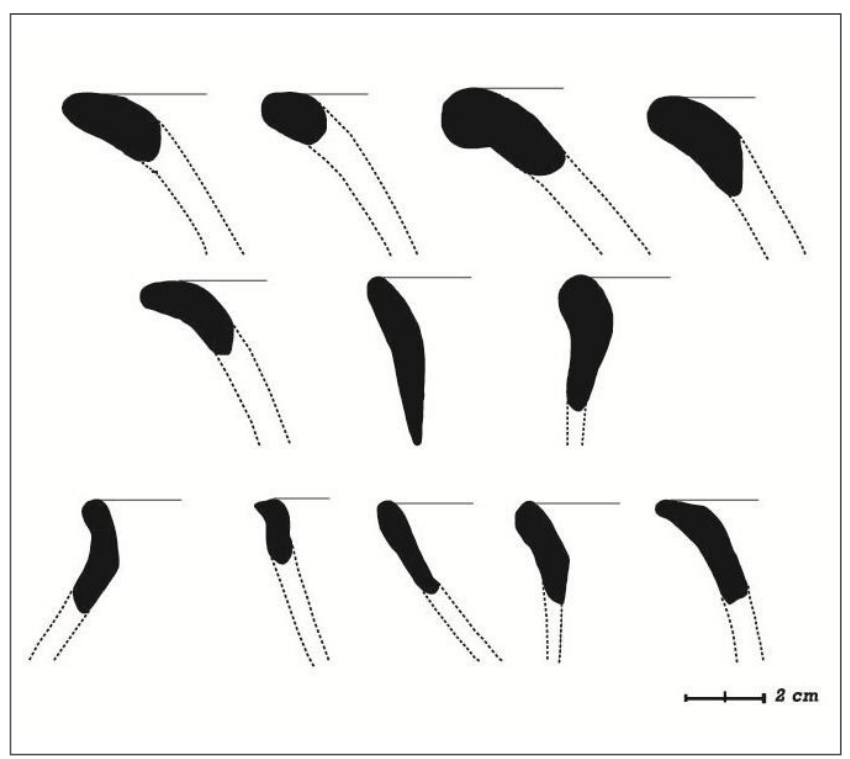

Figura 7. Morfología transversal de bordes en el sitio Toribio
Las estructuras halladas en el sitio Toribio, se encontraron a unos $500 \mathrm{~m}$ del hallazgo y están fuertemente alteradas por la ganadería extensiva que se practica en la zona. En las imágenes aéreas se pueden apreciar bien estos relictos de camellones que, en su mayoría, son imperceptibles en campo debido a que también han perdido su expresión en el microrrelieve local.

Si bien la recuperación de artefactos líticos en ambos sitios fue nula, se registró un hacha trapezoidal pulida, una mano de moler y un metate hallados de manera fortuita por habitantes de la zona en distintos sectores, los cuales reposan actualmente en colecciones particulares.

\section{Discusión}

En la región de Urabá se han documentado numerosos hallazgos arqueológicos, principalmente de cerámica correspondiente a los períodos de desarrollo regional (primeros seis siglos d.C) y de contacto europeo (siglo XVI d.C), los cuales refieren a circunstancias culturales y a artefactos específicos que estarían asociados con patrones regionales. Sin embargo, nunca se habían relacionado las estructuras arqueológicas que aquí se describen y que exigen una contextualización cronológica y paleoambiental, así como una interpretación sociopolítica y económica que considere las interacciones culturales con otros grupos cercanos.

Hace cerca de cuarenta años se reportaron varios sitios en Urabá, con una cerámica bien discernible documentada ampliamente en el sitio El Estorbo, municipio de Turbo (Grupo de Investigación de Arqueología y Prehistoria - GIAP, 1980). Una secuencia seriada de esta cerámica ubicaba estos contextos entre los siglos III a.C y VI d.C. Las ocupaciones de El Estorbo se caracterizaron por ser portadoras de tres distintos tipos cerámicos que se extienden por todo el golfo desde Acandí hasta la cuenca del río Sinú, en el departamento de Córdoba: el tipo "Estorbo rojo pulido", el "Estorbo rojo con engobe blanco" y el "Estorbo blanco (Santos, 1989).

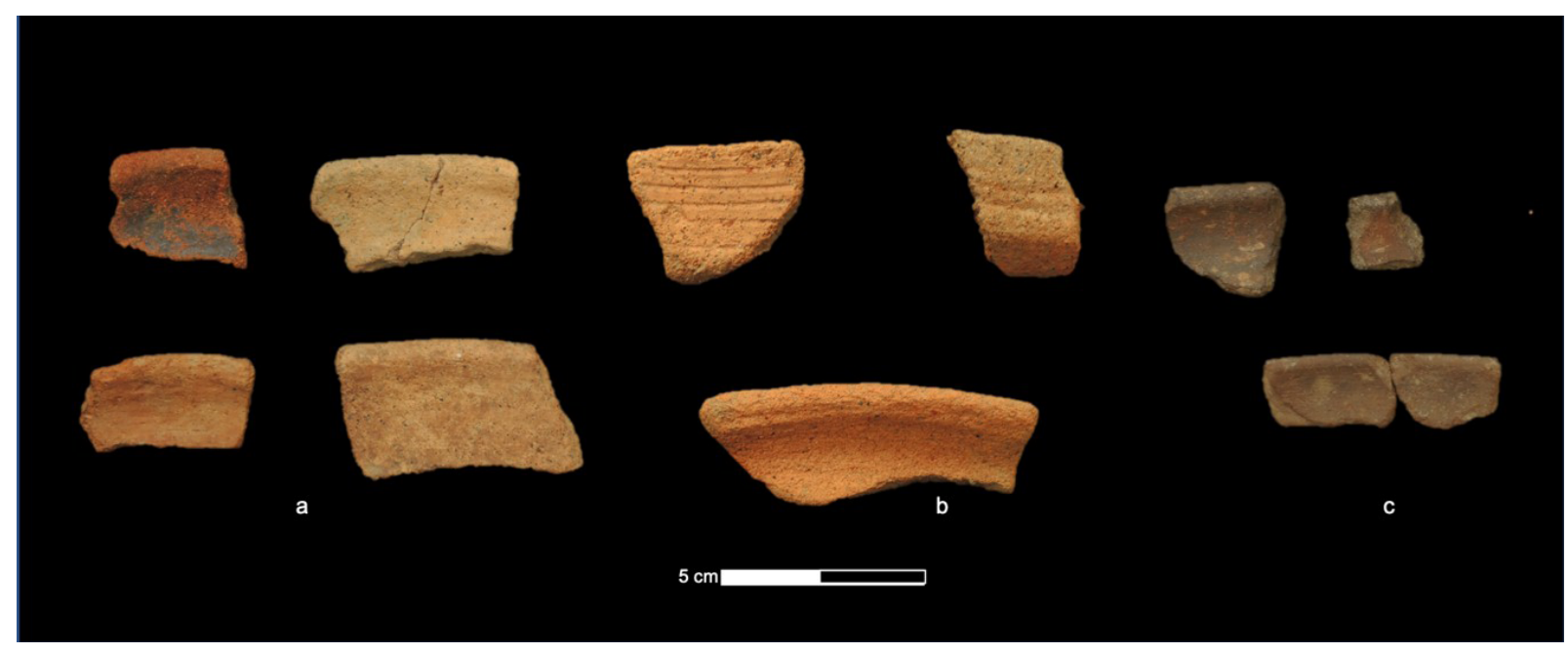

Figura 8. Fragmentos cerámicos del sitio Toribio 
Años más tarde, los mismos investigadores del grupo GIAP obtuvieron fechas radiométricas de los niveles más antiguos del sitio Estorbo I, con lo que se pudo establecer una cronología menos antigua de la que habían estimado inicialmente, con edades de $925 \pm 45$ años a.p (GrN12344) y $1055 \pm 40$ años a.p (GrN-11304) (Santos, 1989). Estas dataciones fueron corroboradas posteriormente por Espinoza \& Nieto (1998), quienes dataron el yacimiento 06 en el municipio de Turbo, asociado con cerámica del mismo tipo, con una fecha de $880 \pm 70$ a.p. (Beta-82003). Pese a ello, en una investigación más reciente, Escobar (2016) reportó tres fechas de los primeros siglos antes de Cristo para la cerámica típica de la fase El Estorbo, esta vez en el sitio San Joaquín, del municipio de Necoclí, las cuales se ajustan mejor a la cronología establecida inicialmente por seriación. Las fechas obtenidas por el autor fueron $2230 \pm 30$ a.p (Beta-443942), 2390 \pm 30 (Beta-443943) y 2020 \pm 30 (Beta443945). Gracias a la correlación de este material con otros hallazgos a nivel regional, la alfarería del Estorbo constituye un referente de la tradición cerámica del golfo de Urabá (Reichel-Dolmatoff, 1997) que se extiende entre los siglos III a.C y XI d.C, aproximadamente (Tabla 2).

Lo cierto es que las características descritas para la cerámica del río León asociada con las estructuras prehispánicas, no parece tener una afinidad tipológica con las tradiciones alfareras reconocidas en el sitio El Estorbo, ya sea por su mal estado de conservación o porque representan tipos esencialmente distintos. En realidad, no se reconoce en ella el conjunto decorativo típico de la tradición modelada incisa de Urabá, aun cuando algunos atributos en la forma de los bordes puedan parecer semejantes. Al contrario, por sus características formales y decorativas, algunos fragmentos remiten más a la cultura material prehispánica reportada en el Chocó y en el occidente de Antioquia (Arcila, 1960; Reichel-Dolmatoff y Reichel-Dolmatoff, 1961; Castillo, 1988; Piazzini, et al., 2009), que a los estilos típicos del complejo Urabá-El Estorbo (Botiva, et al., 1987) o UrabáTierralta, como se le denominó posteriormente (Espinoza \& Nieto, 1998), de tal manera que tanto la filiación cultural como la asignación cronológica deben considerarse con cautela por ahora.
En cuanto a las estructuras hidráulicas, además del sistema de canales y camellones ampliamente estudiados en el río San Jorge, otra evidencia cercana se encuentra en el Darién panameño, donde Martín, et al. (2015) reportaron en el sitio La Chinina un pequeño sistema de canales y camellones similares a los registrados en Urabá. Aunque no se describen las características de la cerámica recuperada, el sitio panameño arrojó dos fechas, $1.410 \pm 30$ años a.p y $570 \pm 40$ a.p, asociadas con la cerámica y las estructuras de tierra.

A falta de fechas concretas en los camellones del río León, la cronología podría estar entre los siglos IV a.C y XII d.C, si se tiene en cuenta la edad de la cerámica del golfo y la de estas tecnologías hidráulicas en Panamá y en las cuencas de los ríos Sinú y San Jorge. Empero, esta cronología representa un rango de tiempo muy amplio para determinar el período de origen y desarrollo de dichas estructuras, y tampoco permite reconocer procesos de interacción cultural o cambios sociopolíticos y ambientales importantes como los que se advierten por las estructuras hidráulicas de la zona.

En este sentido, la cronología es uno de los aspectos básicos que deben resolverse en los sitios de la cuenca del río León. Lo que sí está claro, es que el tiempo asociado con estas estructuras no es el único aspecto crítico, pues su funcionalidad se erige como otro asunto particular que demanda investigaciones a fondo. Los trabajos de Lombardo, et al. (2011) y Rodrigues, et al. (2018) en estructuras similares de la región de Llanos de Mojos en Bolivia, sugieren que las distintas tipologías de canales y camellones descritas por Denevan $(1970,1983)$ en toda América, corresponden a sistemas con funciones distintas. Según los autores, los llamados campos elevados, que constan de un canal con un camellón o montículo contiguo, servirían para el control de las inundaciones, pero sobre todo, para su aprovechamiento en labores agrícolas, en tanto que los campos de zanjas tendrían únicamente una función de drenaje en zonas de inundación periódica.

A pesar de que esta indagación preliminar en las estructuras de Urabá no ha sido suficiente como para reconocer dimensiones detalladas y los métodos de construcción empleados, a la luz de los planteamientos anteriores

Tabla 2. Síntesis de fechas radiométricas obtenidas en la región de Urabá

\begin{tabular}{|c|c|c|c|c|c|c|}
\hline Municipio & Sitio arqueológico & Fecha a.p & $\begin{array}{c}\text { Error } \\
\text { estándar }\end{array}$ & $\begin{array}{c}\text { Código } \\
\text { laboratorio }\end{array}$ & Fecha calibrada & $\begin{array}{l}\text { Referencia } \\
\text { bibliográfica }\end{array}$ \\
\hline \multirow{3}{*}{ Turbo } & \multirow{2}{*}{ El Estorbo I } & 1055 & 40 & GrN-11304 & $905 \mathrm{AD}-1030 \mathrm{AD}$ & \multirow{2}{*}{ Santos, 1989} \\
\hline & & 925 & 45 & GrN-12344 & $1041 \mathrm{AD}-1206 \mathrm{AD}$ & \\
\hline & Yacimiento 06 & 880 & 70 & Beta-82003 & $1045 \mathrm{AD}-1261 \mathrm{AD}$ & Espinoza \& Nieto, 1998 \\
\hline \multirow{3}{*}{ Necoclí } & \multirow{3}{*}{ San Joaquín } & 2230 & & Beta-443942 & 366 BC - 204 BC & \multirow{3}{*}{ Escobar, 2016} \\
\hline & & 2390 & 30 & Beta-443943 & $506 \mathrm{BC}-397 \mathrm{BC}$ & \\
\hline & & 2020 & & Beta-443945 & $49 \mathrm{BC}-57 \mathrm{AD}$ & \\
\hline
\end{tabular}


la variedad de patrones y de tipos de camellones sugiere que existen diferencias importantes en la función de las estructuras al interior del área estudiada, las cuales bien podrían indicar distintas condiciones geomorfológicas, hidráulicas, edáficas y socioculturales que valdría la pena explorar. Hasta que no se adelanten excavaciones estratigráficas y levantamientos minuciosos de la información en los sistemas de canales y camellones detectados, no se podrán resolver estas inquietudes debido a la insuficiencia de datos y a los procesos posteriores a la deposición que han afectado, en mayor o menor medida, el tamaño y la forma original de las estructuras prehispánicas.

Por lo pronto, es claro que la relación entre las estructuras y el manejo de suelos saturados en las tierras bajas es una constante en toda América. El sistema de canales no solo distribuye controladamente las aguas al disipar la energía de las corrientes, sino que incrementa la sedimentación justo en aquellos lugares donde se requiere un aporte de lodos orgánicos para la fertilización de los suelos (Plazas, et al., 1988). Mientras esto acontecía en los canales durante el invierno, los camellones servían para el establecimiento de vías, tumbas u otros campos de cultivo. En diversas regiones del mundo ya se ha documentado ampliamente que la profundidad del suelo en los campos elevados favorece el desarrollo radicular de los cultígenos para su producción de manera intensiva (Erickson, 2006; Renarda, et al., 2012; Boixaderaa, et al., 2019).

Frente a tales bondades, la pregunta es si fueron factores culturales o ambientales los que dejaron en desuso estas estructuras en Urabá, pues histórica y etnohistóricamente no se documentó su uso, cuando hoy en día la cuenca del río León todavía demanda medidas de mitigación de las inundaciones y de sistemas productivos más sostenibles y eficientes.

A pesar de la falta de datos paleoambientales locales, algunos estudios paleoecológicos cercanos no reconocen cambios climáticos significativos en la región entre los siglos X al XVI (Bush \& Colinvaux, 1994; Muñoz, et al., 2017). Si bien no se deben descartar estas causas para explicar el abandono de las estructuras, conviene examinar mejor los conflictos territoriales y las pautas de interacción social que pudieron incidir en ello a la luz de la influencia cultural del Chocó y de la cordillera occidental de Antioquia en la alfarería de la zona, y de las migraciones forzadas documentadas en las crónicas de conquista y en la oralidad de la etnia Tule (Espinoza, 2009).

Sea cual fuere la interpretación de estos hallazgos, resulta de suma importancia indagar sobre las causas e implicaciones socioambientales de una obra semejante en la historia prehispánica de Urabá, toda vez que las formas de organización tecnológica, y las relaciones sociales necesarias para crearla y mantenerla, exigen un conocimiento del entorno y una dinámica de interacción social significativa en el contexto de la economía política prehispánica y de la minimización del riesgo en el ámbito regional.
Por todo ello, es preciso generar conciencia en torno a la conservación de estas evidencias inmuebles, promoviendo nuevos estudios para datarlas, inventariarlas y contextualizarlas cultural y ambientalmente. Solo de esta manera se podrán potenciar académicamente y se integrarán a las dinámicas actuales de uso y gestión del territorio conforme a su vocación patrimonial y ecológica.

\section{Contribución de los autores}

Los autores declaramos haber participado en la escritura del manuscrito y en el proceso de investigación que lo originó. Bibiana Cadena y Estefanía Arroyave contribuyeron con la caracterización y descripción de los sistemas de camellones y canales. Carolina González realizó los análisis de cerámica y su descripción. William Posada hizo la fotointerpretación de las imágenes, diseñó la metodología de clasificación cerámica y realizó las visitas de campo para la descripción de los sitios.

\section{Conflicto de intereses}

Los autores manifiestan la inexistencia de conflictos de intereses en esta investigación y publicación. Hasta el momento el proyecto se financia con recursos de la Universidad de Antioquia.

\section{Agradecimientos}

A Luis Enrique Guzmán del corregimiento Barranquillita y a toda la comunidad del corregimiento que nos escuchó y nos acogió durante nuestras visitas de campo. A Don Jesús María Rodríguez y a su familia por su hospitalidad en la finca El Recreo. Un agradecimiento muy especial para Juan Camilo Gómez, Xiomara Mejía, Juan Pablo Zapata, Juan Fernando Álvarez, Juan Felipe Isaza y Carlos Manuel Hernández, del semillero de investigación ETNOS, por su apoyo y entusiasmo con este proyecto. Por último, extendemos nuestra gratitud a todos los estudiantes del curso de métodos y técnicas arqueológicas del primer semestre del 2018 en el programa de antropología de la Universidad de Antioquia, por su acompañamiento y colaboración durante una de las salidas de campo al río Léon.

\section{Referencias}

Arcila, G. (1960). Investigaciones Arqueológicas En El Carmen de Atrato, Departamento Del Chocó. Boletín de Antropología. 2 (7): 3-38.

Boada, A. (2006). Patrones de asentamiento regional sistemas de agricultura intensiva en Cota y Suba, Sabana de Bogotá. Proyecto de Arqueología "Luis Duque Gómez." Bogotá: Fundación de Investigaciones Arqueológicas, Banco de la República. p. 181.

Boixaderaa, J., Esteban, I., Albert, R., Poch, R.M. (2019). Anthropogenic Soils from Llanos de Moxos (Bolivia): Soils from Precolumbian Raised Fields. Catena. 172: 21-39.

Botiva, A., Enciso, B., Vargas, P. (1987). El Alto Sinú, 17 siglos de asentamiento ribereño, arqueología de rescate. Proyecto Hidroeléctrico Del Alto Sinú Urrá I. Informe Instituto Colombiano de Antropología - Corporación Eléctrica de La Costa Atlántica. Bogotá. p. 352. 
Bray, W. (1990). Cruzando el Tapón del Darién: una visión de la arqueología del istmo desde la perspectiva colombiana. Boletín Museo Del Oro. 29: 3-51.

Broadbent, S. (1968). A Prehistoric Field System in Chibcha Territory, Colombia. Nawapa Pacha - Berkeley. 6: 135-47.

Bruhns, K. (1981). Prehispanic Ridged Fields of Central Colombia. Journal of Field Archaeology. 8 (1): 1-8. Doi: $10.2307 / 529779$

Bush, M. \& Colinvaux, P. (1994). Tropical Forest Disturbance: Paleoecological Records from Darien, Panamá. Ecology. 75 (6): 1761-68.

Castillo, N. (1988). Complejos arqueológicos y grupos étnicos del Siglo XVI en el occidente de Antioquia. Boletín Museo Del Oro. 20: 16-34.

Denevan, W. (1970). Aboriginal Drained-Field Culivation in the Americas. Science. 3946: 647-54.

Denevan, W. (1983). Una perspectiva histórica sobre el descubrimiento de campos elevados (camellones) prehispánicos en Sudamérica. En Agricultura ancestral, camellones y albarradas. contexto social, usos y retos del pasado y del presente. Coloquio Agricultura prehispánica, sistemas basados en el drenaje y en la elevación de los suelos cultivados. Francisco Valdéz (editor). p. 17-24. Quito: Ediciones Abya Yala.

Erickson, C. (2006). El valor actual de los camellones de cultivo precolombinos: experiencias del Perú y Bolivia. En Agricultura ancestral, camellones y albarradas. contexto social, usos y retos del pasado y del presente, Francisco Valdéz (editor). p. 315-39. Quito: Ediciones Abya Yala.

Escobar, W. (2016). Programa de Arqueología preventiva para la construcción de la variante Mellitos. Municipio de Necoclí. Fase de Rescate y monitoreo arqueológico. Informe de arqueología inédito. Medellín: Biblioteca del Instituto Nacional de Antropología e Historia.

Espinoza, I. (2009). Historia y cultura del pueblo Olo Tule de Ipkikuntiwala. Volumen 147. Medellín: Secretaría de Educación y Cultura de Antioquia - Instituto para el Desarrollo de Antioquia - IDEA. p. 342.

Espinoza, I. \& Nieto, L. (1998). Línea de interconexión a $230 \mathrm{Km}$. Cerromatoso-Urabá. Arqueología en Estudios de Impacto Ambiental, Vol 2, ISA. Medellín.

Grupo de Investigación de Arqueología y Prehistoria - GIAP. (1980). Investigación arqueológica y prehistórica de un yacimiento conchal en la costa atlántica colombiana, Turbo - Antioquia. Universidad de Antioquia. Medellín p. 119.

González, L.F. (2011). El Darién. Ocupación, poblamiento y transformación ambiental. Una revisión histórica. Parte I. Medellín: Fondo Editorial ITM. 15 - 58.

Guzmán, H. \& Ceballos, J. (2001). La difluencia del río León hacia el caño Tumaradó. Región de Urabá. Medellín: Instituto de Hidrología, Meteorología y Estudios Ambientales IDEAM. p. 19.

Helms, M. (1979). Ancient Panama: Chiefs in Search of Power. Austin: University of Texas Press. p. 244.

Instituto Geográfico Agustín Codazzi - IGAC. (2007). Estudio semidetallado de suelos de las áreas potencialmente agrícolas. Urabá. Departamento de Antioquia. Subdirección de Agrología. Bogotá: Imprenta Nacional de Colombia. p. 485.

Linne, S. (1929). Darien in the Past: The Archaeology of Eastern Panama and North-Western Colombia. Suecia: Elandors Boktryckeri Aktiebolag. p. 318.
Lombardo, U., Canal-Beedy, E., Fehr, S., Veit, H. (2011). Raised Fields in the Bolivian Amazonia: A Prehistoric Green Revolution or a Flood Risk Mitigation Strategy? Journal of Archaeological Science. 38: 502-12.

Martín, J.G., Mendizábal, T., Scherg, R., Cook, R., Piperno, D. (2015). Pre-Columbian Raised Fields in Panama: First Evidence. Journal of Archaeological Science. 3: 558-64.

Muñoz, P., Gorin, G., Parra, N., Velásquez, C., Lemus, D., Monsalve, C., Jojoa, M. (2017). Holocene Climatic Variations in the Western Cordillera of Colombia: A Multiproxy High-Resolution Record Unravels the Dual Influence of ENSO and ITCZ. Quaternary Science Reviews. 155: $159-78$

Parsons, J. \& Bowen, W. (1966). Ancient Ridged Fields of the San Jorge River Floodplain, Colombia. Geographical Review. 56 (3): 317-43.

Patiño, D. (2006). Campos prehispánicos elevados en la economia Tumaco-Tolita, costa Pacífica de Colombia. En Agricultura ancestral, camellones y albarradas. Contexto social, usos y retos del pasado y del presente. Coloquio Agricultura prehispanica, sistemas basados en el drenaje y en la elevación de los suelos cultivados. Francisco Valdéz (editor). p. 169-88. Quito: Ediciones Abya Yala.

Piazzini, E., Posada, W., Arango, C., Escobar, D. (2009). Arqueología de Frontino: espacio, tiempo y sociedad en el noroccidente de Atioquia durante la época precolombina y colonial. Gobernación de Antioquia - Universidad de Antioquia - Banco de La República. Medellín: Informes de Arqueología. p. 108.

Plazas, C. \& Falchetti, A. (1981). Asentamientos prehispánicos en el bajo río San Jorge. Bogotá: Fundación de Investigaciones Arqueológicas Nacionales. Banco de la República. p. 136.

Plazas, C., Falchetti, A., Sáenz, J., Archila, S. (1993). La sociedad hidráulica Zenú. Estudio arqueológico de 2000 años de historia en las llanuras del caribe colombiano. Bogotá: Banco de la República. p. 308.

Plazas, C., van Der Hammen, T. Botero, P., Sáenz, J., Archila, S. (1988). Cambios ambientales y desarrollo cultural en el bajo río San Jorge. Boletín Del Museo Del Oro. 20: 55-88.

Poveda, E. (2001). Prospección arqueológica Línea Río Sucio, Chigorodó. Ingeoambiente. Bogotá. p. 82.

Reichel-Dolmatoff, G. (1997). Arqueología de Colombia. Biblioteca familiar del Presidente de la República. Bogotá: Presidencia de la República. p. 314.

Reichel-Dolmatoff, G., Reichel-Dolmatoff, A. (1961). Investigaciones arqueológicas en la costa Pacífica. I. Cupica. Revista Colombiana de Antropologia. 10: 237-330.

Renarda, D., Iriarte, J., Birk, J., Rostain, S., Glaser, B., McKey, D. (2012). Ecological Engineers Ahead of Their Time: The Functioning of Pre-Columbian Raised-Field Agriculture and Its Potential Contributions to Sustainability Today. Ecological Engineering. 45: 30-44.

Rodrigues, L., Lombardo, U., Veit, H. (2018). Design of Pre-Columbian Raised Fields in the Llanos de Moxos, Bolivian Amazon: Differential Adaptations to the Local Environment? Journal of Archaeological Science. Reports (17): 366-78.

Rojas, S. (2010). Análisis espacial y patrones de asentamiento en el bajo río San Jorge (Caribe colombiano). Boletín de Antropología. 24 (41): 283-305.

Rojas, S. \& Montejo, F. (2006). Manejo del espacio y aprovechamiento de recursos en la depresión momposina. Bajo Río 
San Jorge. En Agricultura ancestral, camellones y albarradas. Contexto social, usos y retos del pasado y del presente. Francisco Valdéz (editor). Coloquio Agricultura prehispanica, sistemas basados en el drenaje y en la elevación de los suelos cultivados. p. 81-92. Quito: Ediciones Abya Yala.

Román, G. (1985). Primera campaña de investigación arqueológica y prehispánica en el municipio de Necoclí. Medellín: Universidad de Antioquia.

Salgado, H. (1986). Asentamientos prehispánicos en el noroccidente del Valle del Cauca. Bogotá: Fundación de Investigaciones Arqueológicas Nacionales - Banco de la República. p. 160.
Sánchez, C. (2007). Economía y sociedad prehispánica: el uso de la tierra en el Alto Magdalena. Bogotá: Fundación de Investigaciones Arqueológicas, Banco de la República.

Santos, G. (1989). Las etnias prehispánicas y de la conquista en la región de Urabá. Boletín de Antropología. 6 (22 Edición especial): 1-118.

Vélez, L.G. (2011). Urabá prohibido para América: Abya Yala. Proa al golfo... rumbo Pisisí!" Diseño Edotorial Ltda. Bogotá. p. 156. 